\title{
Micropropagation and Field Evaluation of the Pear (Pyrus communis L.) 'IGE 2002', A New Selection of the Cultivar Dr. Jules Guyot
}

\author{
Ignasi Iglesias \\ IRTA-Estació Experimental de Lleida, Rovira Roure 177, 28196 Lleida, Spain \\ Pere Vilardell and Joan Bonany \\ IRTA-Estació Experimental Agrícola Mas Badia, 17134 La Tallada (Girona), Spain \\ Elisabet Claveria, and Ramon Dolcet-Sanjuan ${ }^{1}$ \\ Departament de Genètica Vegetal, Institut de Recerca i Tecnologia Agroalimentàries (IRTA), Centre de \\ Cabrils, Ctra. de Cabrils s/n, 08348 Cabrils (Barcelona), Spain
}

\begin{abstract}
ADDITIONAL INDEX WORDS. in vitro, self-rooting, recalcitrant, varieties, blooming, yield, yield efficiency, size, quality.
Abstract. A new spontaneous mutation of the pear variety Dr. Jules Guyot, named 'IGE 2002', was selected from a pear growing area in Catalonia. The clone was established in vitro from a 40-year-old tree, a highly recalcitrant material unable to root by cuttings. An in vitro micropropagation protocol, with an average multiplication rate of 5, a $90 \%$ rooting, and an acclimation of $79 \%$ of the plantlets, was defined. Self-rooted plants were grown in two experimental stations, covering two distinct fruit growing areas. The main agronomic characteristics of the clone 'IGE 2002' were evaluated during six seasons, 1997 to 2002. Blooming and harvest period were at a similar time than 'Dr. Jules Guyot'. Soluble solids concentration and acidity are also similar to 'Dr. Jules Guyot'. However, at the same harvest time, a lower fruit firmness of 'IGE 2002' in comparison to 'Dr. Jules Guyot' indicated an advanced ripening. In addition, a finer flesh texture of 'IGE 2002' than 'Dr. Jules Guyot', distinguished the former from the later variety. Important differences between both plot sites were found on cumulative fruit yield, fruit size, and fruit size distribution, of 'IGE2002' grown on its own roots. However, the site did not affect the fruit quality parameters. Superior fruit yields were associated with higher vigor and yield efficiency of the self-rooted variety.
\end{abstract}

The pear variety Dr. Jules Guyot, also known in Spain as 'Limonera', was obtained from unknown parents, by M. Baltet (Trayes, France), in 1870. Its culture was extended to Spain where after 1940 it reached a great importance. At the present time, with 4.500 ha dedicated to its cultivation, it is the second most important variety in Spain after 'Blanquilla'. More than $85 \%$ of its cultivation is located in Catalonia, in the northeast of Spain. Because of its early harvest export is the main destination of 'Dr. Jules Guyot'. In spite of the importance of this variety in Europe, selection works have not been carried out.

Sexual and asexual propagation are common practices for obtaining seedling or cloned pear rootstocks on which to graft varieties. Hence, pear varieties are propagated by budding or grafting on rootstocks. Due to the scarce success in rooting pear cuttings, this asexual propagation method is not employed in propagating pear cultivars. An alternative to this limitation is the development of an in vitro micropropagation method to self-root a variety. Field performance evaluations of self-rooted varieties were first reported for apple (Jones et al., 1979; Webster et al., 1985; Zimmerman and Steffens, 1989). With the development of appropriate micropropagation techniques for each species, field trials with own-rooted varieties have been reported for pear (Neri et al., 1989), and peach and nectarine (Liverani et al., 1989). During the last decade more studies have focused on the field performance of micropropagated apple (Larsen and Higgins, 1993), pear (Carrera and Gomez-Aparisi, 1998; Predieri, 2002; Stanica et al., 2002; Iglesias et al., 2003), peach (Hammerschlag and Scorza, 1991), walnut (Dolcet-Sanjuan et al.,

Received for publication 21 Aug. 2003. Accepted for publication 15 Dec. 2003. This work was supported in part by the CICYT project AGF1998-0277-C04-03. Use of trade names does not imply endorsement of the products named nor criticism of similar ones not named.

1To whom correspondence should be addressed; e-mail ramon.dolcet @ irta.es.
1996; Lopez, 2001), and pistachio (Dolcet-Sanjuan and Claveria, 1995). In vitro self-rooting has been limited to a number of wellknown pear cultivars such as 'Williams', 'Red Williams', 'Bartlett', and 'Conference'. Since the pear consumer accepts more easily the improvements in a standard variety than those that are completely new, the selection of spontaneous or induced mutations can be important for pear breeding (Predieri, 2002). The work described herein is the first reporting of the in vitro propagation, self-rooting, and field performance of a new pear variety obtained from a field spontaneous mutation of a known cultivar.

Development of new plantations of this variety is limited by its slow production phase initiation, which could expand to 5 years. Conventionally, this variety was grafted on quince (Cydonia oblonga $\mathrm{L}$.), due to the undesirable higher vigor and small fruit size observed with Pyrus seedling rootstocks. Due to incompatibility with the quince rootstocks, the graft point was placed underground to favor root development on the variety. However, this technique usually results in a lack of homogeneity which can be overcome with the use of inter-stems (Baldini et al., 1977). Self-rooting could be an alternative to shorten the nonproductive phase and solve the incompatibility problems with quince rootstocks, without affecting fruit diameter and cumulative production.

Herein we report 1) an in vitro micropropagation protocol of a selected spontaneous mutation of P. communis 'Dr. Jules Guyot', named 'IGE-2002', from a mature elite tree and 2) describe the agronomical characteristics, vegetative growth and fruit production of the self-rooted trees.

\section{Materials and Methods}

Plant material. The genotype used for this study was Pyrus communis L. 'IGE-2002' selected in the field as an spontaneous 
mutation of the variety Dr. Jules Guyot or Limonera. In vitro shoot-tip cultures of this clone were established from an orchard with 40-year-old trees located at the village of Granja d'Escarp, in Catalonia. This clone of 'Dr. Jules Guyot' was selected after a prospect performed in 1993, in which early maturity and flesh with a smooth, nongranular texture, were the main characters of interest. Every other week, before budbreak, and during new shoot growth, trees were sprayed with a fungicide (fixed copper, 8-oxiquinolein sulfate, captan, or benomyl). All treatments included $0.1 \%(\mathrm{v} / \mathrm{v})$ Tween-20.

Medium ANd Culture Conditions. During establishment and multiplication phases, the explants were cultured in MS-M medium which consisted of mineral nutrients devised by Murashige and Skoog (1962), except for 3\% (w/v) sucrose, myo-inositol (100 $\left.\mathrm{mg} \cdot \mathrm{L}^{-1}\right)$, thiamine- $\mathrm{HCl}\left(1 \mathrm{mg} \cdot \mathrm{L}^{-1}\right)$, nicotinic acid $\left(1 \mathrm{mg} \cdot \mathrm{L}^{-1}\right)$, pyridoxine-HCl $\left(1 \mathrm{mg} \cdot \mathrm{L}^{-1}\right)$ and $0.7 \%(\mathrm{w} / \mathrm{v})$ Difco Bacto-Agar. The $\mathrm{pH}$ was adjusted to 5.7 before autoclaving. The medium used for rooting (MS-R) was similar to MS-M medium but with one-half the concentration of macronutrients. MS-M medium was supplemented with $5 \mu \mathrm{M} \mathrm{N}^{6}$-benzyladenine (BA), added before autoclaving. Growth regulators, indole-3-butyric acid (IBA) and $\alpha$-naphthaleneacetic acid(NAA), were dissolved in dimethylsulfoxide(DMSO) (Schmitz and Skoog, 1970) which acts as a sterilant, and was added to the root induction medium after autoclaving $(50 \mu \mathrm{L}$ DMSO/100 mL medium). All chemicals were supplied by the Sigma Chemical
Co. (Alcobendas, Madrid), and Difco Bacto-Agar was supplied by Difco Laboratories (Detroit, Mich.). During establishment and shoot multiplication, all cultures were kept at a temperature of 28 ${ }^{\circ} \mathrm{C}$ under a photoperiod of $16 \mathrm{~h}$ of cool-white fluorescent light (70 $\left.\mu \mathrm{mol} \cdot \mathrm{m}^{-2} \cdot \mathrm{s}^{-1}\right)$.

EXPLANT ESTABLISHMENT AND SHOOT MULTIPLICATION. In April 1993, newly growing shoots from two field-grown trees were harvested and used as source of explants. Explants were 1- to 2-cm-long nodal segments with two to three axillary buds. The explants were washed for $1 \mathrm{~h}$ by stirring in distilled water and surface-sterilized in $70 \%$ ethanol for $1 \mathrm{~min}$, followed by $0.5 \%$ (w/v) $\mathrm{NaOCl}$ with $0.1 \%$ (v/v) Tween-20 for $10 \mathrm{~min}$. Each explant was rinsed individually three times with sterile distilled water, trimmed, and cultured in a tube containing $15 \mathrm{~mL}$ of MS-M with $5 \mu \mathrm{M}$ BA. During the first 12 weeks, shoot-tip explants were subcultured weekly. Shoots that appeared uncontaminated were screened further for bacterial contamination in 523 medium (Viss et al., 1991). Streaked plates were incubated for 2 weeks, in the dark, and at $28^{\circ} \mathrm{C}$. Explants that showed bacterial growth on this medium were discarded. Branching and multiplication started about 16 weeks after initiation. For shoot multiplication, shoots or segments of at least $1-\mathrm{cm}$-long were transferred every 4 weeks to flasks containing $100 \mathrm{~mL}$ of MS-M medium supplemented with $5 \mu \mathrm{M}$ BA. Ten segments were transferred to each flask.

Shoot MUltiplication AND PRESERVATiOn IN DOUble-PHASE.
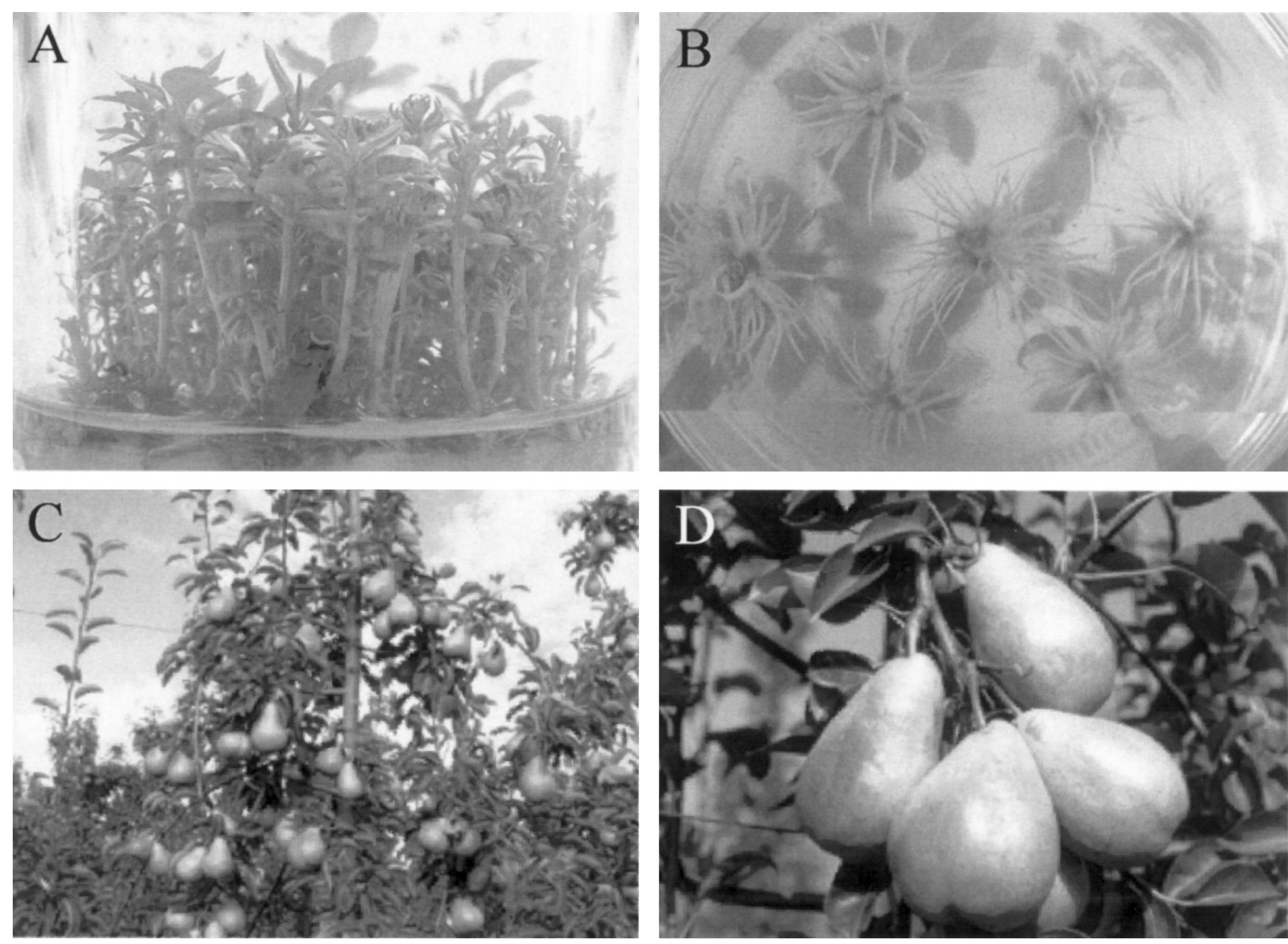

Fig. 1. In vitro shoot multiplication culture by axillary branching (A), rooting (B), tree during production in the field trial (C), and fruit of 'IGE2002' (D). 
Branching and multiplication, 32 weeks after initiation, was high enough to set aside a stock of plant material under slow growth conditions. Shoot of at least 1-cm long were transferred to flasks containing $100 \mathrm{~mL}$ of MS-M medium supplemented with $5 \mu \mathrm{M}$ BA and $0.8 \%$ (w/v) Difco Bacto-Agar. Ten segments were transferred to each flask. Four weeks later $50 \mathrm{~mL}$ of liquid MS-M medium supplemented with $5 \mu \mathrm{M}$ BA were added to each flask. The same operation, but adding $25 \mathrm{~mL}$ of the liquid MS-M medium, was performed 8 weeks after culture in the solid phase. Cultures were kept at a temperature of $25^{\circ} \mathrm{C}$ under a photoperiod of $16 \mathrm{~h}$ of coolwhite fluorescent light $\left(70 \mathrm{\mu mol} \cdot \mathrm{m}^{-2} \cdot \mathrm{s}^{-1}\right)$, for a total of 12 weeks.

IN VITRO ROOT INDUCTION AND ELONGATION. For root induction and elongation, well developed 3- to 4-cm-long shoots were transferred to MS-R medium. The experiments were conducted with micropropagated shoots from the seventh through the fifteenth subculture, 40 to 72 weeks after initiation, respectively. During root induction and elongation, cultures were kept at $28{ }^{\circ} \mathrm{C}$ under a photoperiod of $16 \mathrm{~h}$ of cool-white fluorescent light $\left(35 \mu \mathrm{mol} \cdot \mathrm{m}^{-2} \cdot \mathrm{s}^{-1}\right)$. In the first two-factor experiment, the effects of various IBA and NAA concentrations $(0,1,3.2,10$, or $31.6 \mu \mathrm{M})$ were examined. Shoots were grown on auxin-containing medium for 5 days and then on auxin-free medium for 3 weeks.

In the second one-factor experiment, the effects of four distinct root induction and elongation treatments were determined. For three of these treatments, the choice of IBA at $10 \mu \mathrm{M}$ in the root induction medium was based on the results of the first experiment. In addition, the effects of a 15-s-long dip in a $10 \mathrm{~mm}$ IBA (in $50 \%$ methanol) solution was tested as a root induction treatment (Dolcet-Sanjuan et al., 1990). The addition of $150 \%$ (v/v) exfoliated vermiculite (Termita; Asfaltex S.A., Barcelona, Spain) to the MS-R auxin-free medium was tested in the root elongation phase (Jay-Allemand et al., 1992).

Each experiment, with a completely randomized design, consisted of three randomly selected replicate flasks with 10 shoots each per treatment level. These explants were from shoot-tip multiplication cultures. The experiments were repeated three times. The percentage of rooted shoots per flask was determined. Statistical tests included analysis of variance, separation of means by Fisher's protected LSD, and planned contrasts (Petersen, 1985).

Acclimation To soil. Rooted plantlets were washed and potted in trays with steam-sterilized $\left(100{ }^{\circ} \mathrm{C}, 1 \mathrm{~h}\right) 1$ peat : 1 perlite : 1 sand : 1 water (by volume). The acclimation phase, in a plastic tunnel with a fog system was 2 weeks long. Acclimated plants were transferred to a shaded greenhouse for hardening, in polypropylene containers with 2 peat : 1 sand (by volume). More than 200 selfrooted plants were produced for field trials.

FIELD PLOTS. In February 1997 there was enough material to plant scions $1.40 \mathrm{~m}$ high and 10 to $12 \mathrm{~mm}$ in diameter without feathers. Six trees were planted in the Experimental Station of Lleida (EEL) and six trees on the Experimental Station of Mas Badia (EEMB). The planting distance was $4 \times 1.5 \mathrm{~m}$ using the central axis as a training system. The six trees in each site were planted as a single plot without replications. In EEL trees were growing on Tipic Xerofluvent, coarse-silty, mixed (calcareous), mesic soil that averages $0.85 \mathrm{~m}$ depth, moderately basic $(\mathrm{pH} 8.2)$, with an average free $\mathrm{CaCO}_{3}$ content of 5.8\%. In EEMB the pH was 8.1, sandy texture and free $\mathrm{CaCO}_{3}$ content of $3.5 \%$. The annual rainfall is $394 \mathrm{~mm}$ and $618 \mathrm{~mm}$, for EEL and EEMB respectively, with warm dry weather in summer reaching maximum temperatures of $\approx 40^{\circ} \mathrm{C}$ in EEL and $36^{\circ} \mathrm{C}$ in EEMB.

Fruit Quality MEASURES. In the 1998-2002 period the blooming time, harvest dates, yield, vigor (section of the trunk at $20 \mathrm{~cm}$ from the soil level), size distribution, fruit weight and quality parameters in a sample of 20 fruits were recorded. In order to compare the ripening stage, fruits of 'IGE 2002' and 'Dr. Jules Guyot' were harvested on the same dates. Flesh firmness (in kg) was determined with an Effegi portable penetrometer (Effegi, Alfonsina, Italy) with an 8-mm tip, taking two readings from two opposite peeled sides, of 20 fruit, for each season. Soluble solids concentrations (SSC), expressed in percent, were determined by measuring the refractive index on blended composite wedges from 20 unpeeled pears using an Atago-Palette 100 digital calibrated refractometer (Atago Co., Tokyo, Japan). Titratable acidity (TA) was determined for the same composite by titrating to final $\mathrm{pH}$ of 8.2 with $0.1 \mathrm{~N} \mathrm{NaOH}$ and expressed as $\mathrm{g} \cdot \mathrm{L}^{-1}$ malic acid.

\section{Results and Discussion}

Micropropagation. Establishment of 'IGE2002' in vitro shoot tip cultures from a 40-year-old plantation encountered problems of internal bacterial contamination of the explants. Fungicide treatments before budbreak and during new shoot growth help to reduce external contamination, but most of the explants showed internal bacterial contamination during the first in vitro subcultures. Apparent contamination was confirmed by streaking plates of 523-medium with the base of each explant. Only $5 \%$ of the explants were free of contamination. The MS-M medium supplemented with $5 \mu \mathrm{M}$ BA was adequate to initiate shoot branching during establishment and promote axillary shoot proliferation during the multiplication phase. Shoot-tip cultures on MS-M medium, with subcultures every 4 weeks, had an average multiplication rate of five new shoots per explant. Multiplication and storage in the double-phase culture system, with two additions of liquid medium and subcultures every 12 weeks, had multiplication rates of up to eight new shoots per

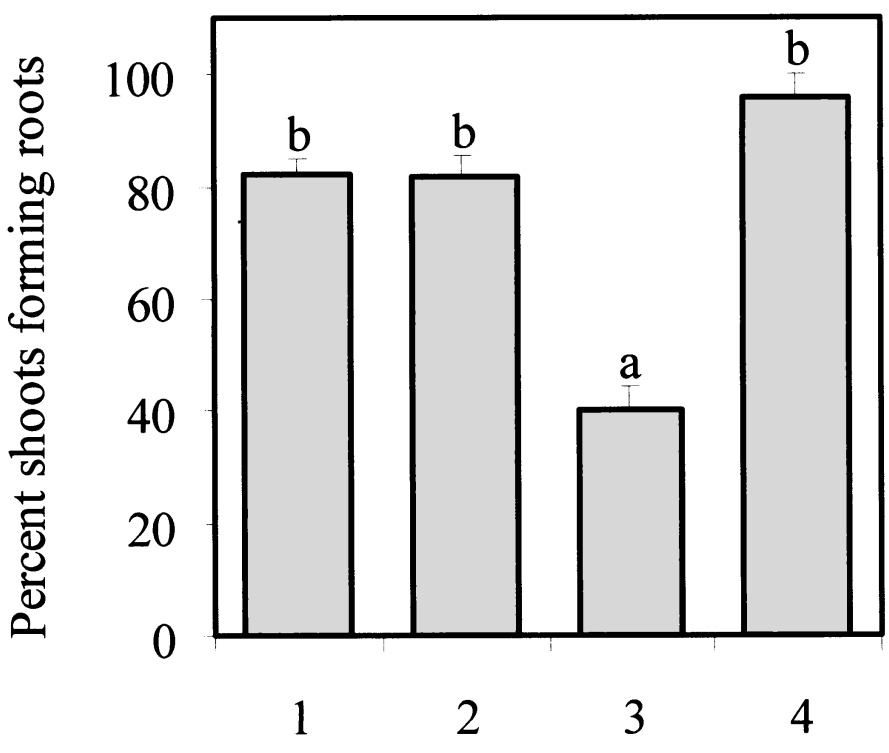

Root induction treatment

Fig. 2. Effects of four root induction and elongation conditions on the percentage of Pyrus comunis 'IGE2002' shoots forming roots after 3 weeks in the root elongation medium. Root induction treatments: 1) 5-d culture in half strength MS medium with $10 \mu \mathrm{M}$ IBA, root elongation in agar containing medium; 2) equal to treatment 1 but with root elongation in vermiculite containing medium; 3 ) equal to treatment 2 but with a 2 -d culture in auxin-containing medium; 4) dip in $10 \mathrm{~mm}$ IBA followed by elongation in vermiculite-containing medium. Treatment means with the same letter are not significantly different in the Fisher's protected least significant difference $(P=0.05)$. Vertical bars $=\mathrm{sE}$. 
Table 1. Fruit size and quality parameters ${ }^{\mathrm{z}}$ of 'IGE2002' and 'Dr. Jules Guyot' in the Experimental Station of Lleida (EEL) and the Experimental Station of Mas Badia (EEMB).

\begin{tabular}{|c|c|c|c|c|}
\hline \multirow[b]{3}{*}{ Parameter } & \multicolumn{4}{|c|}{ Field plot site } \\
\hline & \multicolumn{2}{|c|}{ EEL } & \multicolumn{2}{|c|}{ EEMB } \\
\hline & 'IGE2002' & 'Dr. Jules Guyot' & 'IGE2002' & 'Dr. Jules Guyot' \\
\hline Mean fruit size (mm) & 62.7 & 65.3 & 64.8 & 69.7 \\
\hline Percent of total yield at first picking ( $>60 \mathrm{~mm}$, diameter) & 87.5 & 91.3 & 68.1 & 73.5 \\
\hline Firmness (kg) & 5.9 & 6.6 & 6.0 & 6.5 \\
\hline Soluble solids concentration (Brix degrees) & 10.5 & 10.9 & 9.3 & 10.2 \\
\hline Titratable acidity $\left(\mathrm{g} \cdot \mathrm{L}^{-1}\right.$ malic acid $)$ & 2.8 & 3.0 & 2.9 & 3.3 \\
\hline
\end{tabular}

zValues are means of the 1998-2002 period.

explant (Fig. 1A).

Rooting of micropropagated shoots in MS-R medium supplied with IBA had a higher percentage of shoots forming roots than with NAA (data not shown). At a concentration of $10 \mu \mathrm{m}$ IBA the maximum percentage of rooting reached $82 \%$ (treatment 1 , Fig. 2) while a higher concentration induced too much callus. Rooted shoots showed an increased number of roots per shoot (Fig. 1B). In a second rooting experiment, root elongation in a vermiculite-containing medium (Jay-Allemand et al., 1992) had the same percentage of shoots $(81.9 \%)$ forming roots (treatment 2, Fig. 2), but with the beneficial effects of inducing the formation of thinner and less friable roots. Shortening the time of culture in auxin-containing medium from 5 to $2 \mathrm{~d}$ before transfer to vermiculite-containing medium (treatment 3, Fig. 2), reduced the presence of callus but also reduced the percentage of shoots forming roots to $40 \%$. More interestingly, substituting the culture in IBA-containing medium by a dip in a $10 \mathrm{~mm}$ IBA solution before transfer to vermiculite-containing medium (treatment 4, Fig. 2) improved rooting percentage to $95.9 \%$, reducing the number of transfers and the costs of rooting. Differences between treatments 1, 3 or 4 , on the percentage of shoots forming roots were not significant $(P$ $=0.321$ ). Therefore a 5-d-long culture in MS-R medium supplemented with $10 \mu \mathrm{M}$ IBA followed by 3-week-long culture in auxin free medium, with or without vermiculite, or a dip in $10 \mathrm{~mm}$ IBA followed by root elongation in vermiculite medium were the best treatments to produce rooted plantlets. Seventy nine percent of the plantlets produced were successfully acclimated to soil conditions and grown in the green house before transfer to the field.

Using soft-wood or semi-hardwood cuttings of 'IGE 2002', with or without an auxin treatment (5-s-long dip in 4000 ppm IBA dissolved in 50\% methanol) to induce rooting, the number of cuttings forming roots only reached $0.1 \%$. Only in vitro techniques permitted the production of self-rooted plants of this variety, in sufficient number to set a field trial. A total of 360 plants were produced by in vitro micropropagation.

Table 2. Blooming period, harvest time, cumulative yield, vigor, and yield efficiencyz of 'IGE2002' in the Experimental Station of Lleida (EEL) and the Experimental Station of Mas Badia (EEMB)

\begin{tabular}{lcc}
\hline \multirow{2}{*}{ Parameter } & \multicolumn{2}{c}{ Field plot site } \\
\cline { 2 - 3 } Blooming period & 30 Mar.-5 Apr. & 31 Mar.-7 Apr. \\
Full bloom & 29 Mar.-4 Apr. & \\
Harvest period & 19 July-27 July & 29 July-5 Aug. \\
Full bloom til harvest (d) & 114 & 117 \\
Cumulative yield $(\mathrm{kg} / \mathrm{tree})$ & 102.6 & 14.2 \\
Trunk cross sectional area $\left(\mathrm{cm}^{2}\right)$ & 57.2 & 12.9 \\
Yield efficiency $\left(\mathrm{kg} \cdot \mathrm{cm}^{-2}\right)$ & 1.8 & 1.1 \\
\hline
\end{tabular}

zValues are means of the 1997-2002 period.
Field EVAluation. For the same date of harvest, the lower fruit firmness of 'IGE2002' in comparison to 'Dr. Jules Guyot' (Table 1) would indicate an earlier fruit ripening of 'IGE 2002'. Small differences in the soluble solids content and titratable acidity were observed between both clones (Table 1). The texture of 'IGE-2002' was finer and less gritty than 'Dr Jules Guyot', making it more pleasant to the consumer with no difference in fruit flavor. These quality parameters clearly differentiated the selected spontaneous mutation 'IGE2002' (Fig. 1C and D) from the original 'Dr. Jules Guyot'.

The blooming time of 'IGE 2002' was intermediate and similar to 'Limonera', 'Conference' and 'William's'. The harvest time is the middle of July after 'Ercolini'. The blooming and harvest time were 1 week to $10 \mathrm{~d}$ earlier at the EEL than the EEMB field plots (Table 2).

Yields show important differences between sites and those from the EEL were higher than the EEMB (Table 2, Fig. 3). These higher yields in EEL were also related with higher tree vigor and a better yield efficiency than in EEMB (Table2). The differences in tree vigor between sites are mainly due to different soil conditions and a minor degree to weather conditions. The similarities between the field plot site from where 'IGE2002' was isolated and the soil conditions at the EEL, could explain the better adaptation of this selection to the EEL than the EEMB.

Although the fruit quality parameters (Table 1) were in general similar in both sites, EEL and EEMB, the average percentage of total yield at first picking was higher in EEL than in EEMB. Mean values of fruit size distribution during the five seasons, 1998 to 2002 (Fig. 4) at EEL shows a dominant size of 60 to $70 \mathrm{~mm}$, reaching the mean size of $62.7 \mathrm{~mm}$ (Table 1). At the EEMB the dominant size was also 60 to $70 \mathrm{~mm}$ but with higher averages of 70 to 80 and $>80 \mathrm{~mm}$ (Fig. 4). Mean size was slightly higher at the EEMB than EEL field plot site, and reached $64.8 \mathrm{~mm}$ (Table 2), probably due to the lower production in EEMB. Fruit size increased and became more homogeneous as the trees aged. For this reason fruit size of 'IGE2002' during the first years of growth was more similar to the 'Dr. Jules Guyot' grafted on seedlings of pear than to this variety grafted on quince (data not shown). Similar results on fruit size were reported for the 'Conference' pear by Carrera and Gomez-Aparisi (1998) and Iglesias et al. (2003). However, Neri et al. (1989) found that fruit quality, shape, size and harvest date of the self-rooted 'Bartlett' trees were similar to those grafted on 'Quince A EM'.

In conclusion, a micropropagation method has been developed to self-root a selected spontaneous pear mutation 'IGE2002' of 'Dr. Jules Guyot' or 'Limonera' from a 40-year-old plantation, a highly recalcitrant material to conventional propagation by cuttings. As with other pear varieties (Stanica et al., 2002) the results show that this pear selection on its own roots can be planted in pear orchards, 


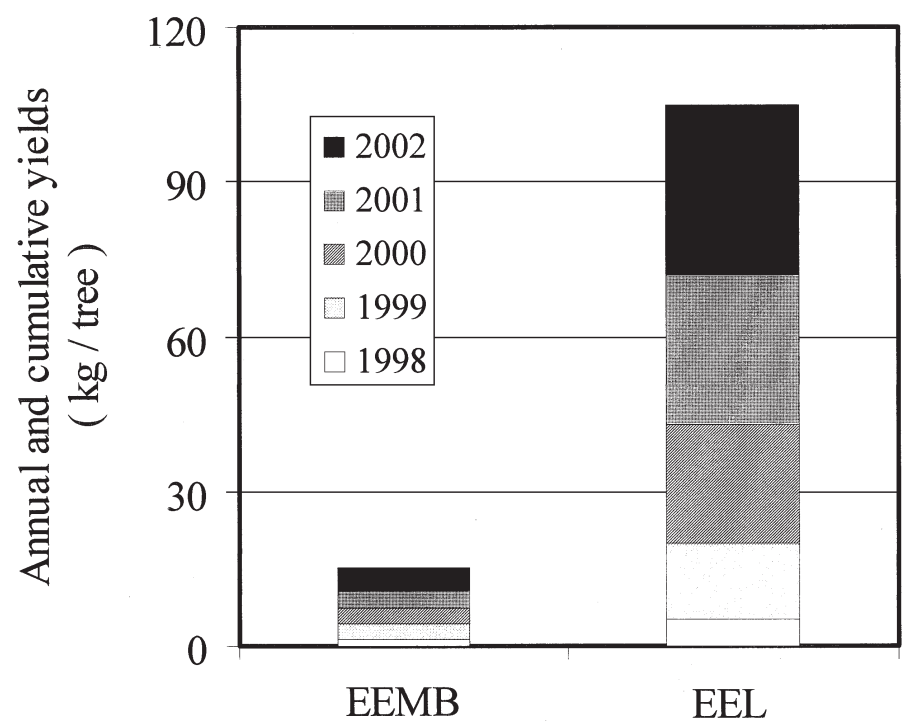

Field plot site

Fig. 3. Annual and cumulative yields of 'IGE-2002' in the Experimental Station of Lleida (EEL) and the Experimental Station of Mas Badia (EEMB) field plots, from 1998 to 2002 .

with advantages in early fruit bearing. Since 'IGE2002' has an early maturity, a lower fruit firmness, and a finer and less gritty texture than 'Dr Jules Guyot', it might be more acceptable to the growers and consumers. Our future efforts will focus on comparing the performance of this variety grafted on commercial rootstocks or with inter-stems when quince is used as rootstock.

\section{Literature Cited}

Baldini, E., G. Costa, and S. Sansavini. 1977. A twelve year survey on various interstocks on Beurre Bosch, Beurre Anjou, Clapp's Favourite, and William's pear trees on Quince A. Acta Hort. 69:105-112.

Carrera, M. and J. Gomez-Aparisi. 1988. Behavior of 'Conference' pear, self-rooted or grafted on different rootstocks. Acta Hort. 475:143-147.

Dolcet-Sanjuan, R. and E. Claveria. 1995. Improved shoot-tip micropropagation of Pistacia vera L. and the beneficial effects of methyl jasmonate. J. Amer. Soc. Hort. Sci. 120:938-942.

Dolcet-Sanjuan, R., E. Claveria, A. Camprubi, V. Estaun, and C. Calvet. 1996. Micropropagation of walnut trees (Juglans regia L.) and response to arbuscular mycorrhizal inoculation. Agronomie 16:563-571.

Dolcet-Sanjuan, R., D.W.S. Mok, and M.C. Mok. 1990. Micropropagation of Pyrus and Cydonia and their responses to Fe-limiting conditions. Plant Cell Tissue Organ Cult. 21:191-199.

Hammerschlag, F.A. and R. Scorza. 1991. Field performance of micropropagated, own-rooted peach trees. J. Amer. Soc. Hort. Sci. 116: 1089-1091.

Iglesias, I., L. Asín, R. Montserrat, P. Vilardell, J. Carbó, and J. Bonany. 2003. Performance of some pear rootstocks in Lleida and Girona (NESpain). 1st Intl. Symp. rootstocks for deciduous fruit tree species. ISHS, Zaragoza (Spain). Acta Hort. (in press).

Jay-Allemand, C., P. Capelli, and D. Cornu. 1992. Root development of in vitro hybrid walnut microcuttings in a vermiculite-containing gelrite medium. Scientia Hort. 51:335-342.

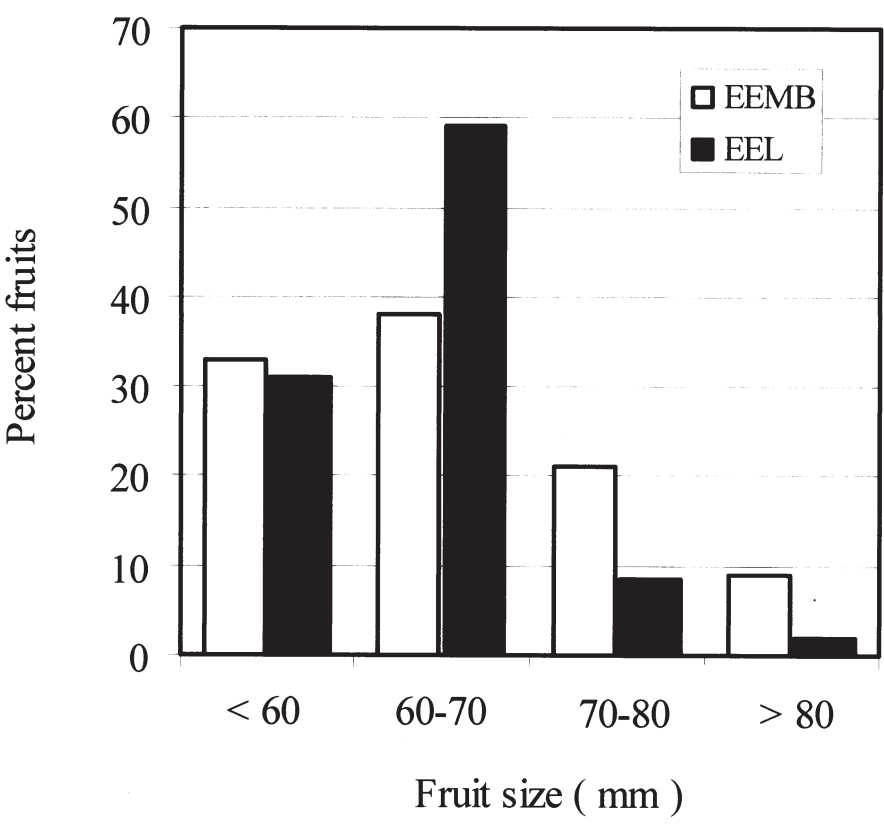

Fig. 4. Average fruit size distribution of 'IGE-2002' in the Experimental Station of Lleida (EEL) and the Experimental Station of Mas Badia (EEMB) field plots, from 1998 to 2002.

Jones, O.P., C.A. Pontikis, and M.E. Hopgood. 1979. Propagation in vitro of five apple scion cultivars. J. Hort. Sci. 54:155-158.

Larsen, F.E. and S.S. Higgins. 1993. Growth and fruit production of young micropropagated apple (Malus domestica Borkh.) trees. Scientia Hort. 53:205-211.

Liverani, A., D. Cobianchi, F.R. de Salvador, O. Insero, and A. Minguzzi. 1989. Field performance of two peach and nectarine cultivars propagated in vitro. Acta Hort. 254:41-46.

Lopez, J.M. 2001. Field behaviour of self-rooted walnut trees of different cultivars produced by tissue culture and planted in Murcia (Spain). Acta Hort. 544:543-546.

Murashige, T. and F. Skoog. 1962. Arevised medium for rapid growth and bio assays with tobacco tissue cultures. Physiol. Plant. 15:473-497.

Neri, D., S. Sansavini, and M. Capobianco. 1989. Performance of micropropagated and budded pear trees: Interaction between scion and dwarf-quince clones. Acta Hort. 256:69-76.

Petersen, R.G. 1985. Design and analysis of experiments. 1st ed. Marcel Dekker, NewYork.

Predieri, S. 2002. The importance of induced mutations in pear improvement. Acta Hort. 596:161-166.

Schmitz, R.Y. andF.Skoog. 1970. The use of dimethylsulfoxide as a solvent in the tobacco bioassay for cytokinins. Plant Physiol. 45:537-538.

Stanica, F., M. Dumitrascu, and A. Peticila. 2002. Behaviour of three pear cultivars propagated in vitro and self-rooted, on Tatura trellis canopy. Acta Hort. 596:647-649.

Viss, P.R., E.M. Brooks, and J.A. Driver. 1991. A simplified method for the control of bacterial contamination in a woody plant tissue culture. In Vitro Cell. Dev. Biol. 27P:42.

Webster, A.D., V.H. Oehl, J.E. Jackson, and O.P. Jones. 1985. The orchard establishment, growth and precocity of four micropropagated apple scion cultivars. J. Hort. Sci. 60:169-180.

Zimmerman, R.H. and G.L. Steffens. 1989. Management of self-rooted tissue-cultured apple trees: I. Orchard establishment and early growth. Acta Hort. 239:117-120. 